\title{
Analysis of Climate Change and Circulation Features of Frost Days in Hunan Province, China in Recent 67 Years
}

\author{
Zhen Li1,2, Qinglong You1 ${ }^{*}$, Hongwu Liu ${ }^{3}$, Zhonghai Yin ${ }^{3}$, Lijie Duan" \\ ${ }^{1}$ Nanjing University of Information Science \& Technology, Nanjing, China \\ ${ }^{2}$ Meteorological Bureau of Hunan Provincial, Changsha, China \\ ${ }^{3}$ Meteorological Observatory of Hunan Province, Changsha, China \\ ${ }^{4}$ The Climate Center of Hunan Province, Changsha, China \\ Email: ^qlyou@fudan.edu.cn
}

How to cite this paper: Li, Z., You, Q. L., Liu, H. W., Yin, Z. H., \& Duan, L. J. (2019). Analysis of Climate Change and Circulation Features of Frost Days in Hunan Province, China in Recent 67 Years. Journal of Geoscience and Environment Protection, 7, 124-137.

https://doi.org/10.4236/gep.2019.711009

Received: July 24, 2019

Accepted: November 22, 2019

Published: November 25, 2019

Copyright $\odot 2019$ by author(s) and Scientific Research Publishing Inc. This work is licensed under the Creative Commons Attribution International License (CC BY 4.0).

http://creativecommons.org/licenses/by/4.0/

\begin{abstract}
This paper provides a basis for crop structure adjustment and selection of suitable growth period varieties in Hunan Province of China, and improves the predictive capacity of Hunan's abnormal frost disasters to defend against frost disasters effectively. Using the frost date data of 97 meteorological monitoring stations in Hunan Province from 1951 to 2017, statistical analysis was carried out on the variable characteristics of frost days, initial and final frost days and frost-free periods. The NCEP/NCAR data were used to study the circulation characteristics of the province's frosty weather by linear and polynomial fitting methods to show that: 1) The frost days decrease $-0.1 \mathrm{~d} / \mathrm{a}$ from December to January. 2) The inter-annual rate of change in the initial and final frost days and frost-free period is large, and the average first frost day showed a delayed trend $(0.13 \mathrm{~d} / \mathrm{a})$. The average final frost day showed an early change trend $(-0.12 \mathrm{~d} / \mathrm{a})$, and the average frost-free period showed an extended trend $(0.22 \mathrm{~d} / \mathrm{a}) .3)$ The frosty weather in Hunan Province has obvious geographical distribution characteristics. The first frost day showed distribution characteristics of "early in the east and later in the west", and the final frost day showed the distribution characteristics of "early in the south and later in the north". The frost-free period showed the distribution pattern of "long in the south and short in the north". 4) The circulation characteristic values of the frosty days are as follows: $500 \mathrm{hPa}$ East Asian trough is stable, and the temperature field has a cold tongue of $-40^{\circ} \mathrm{C}$. The $-12^{\circ} \mathrm{C}$ line is located in south part of Hunan and the $0^{\circ} \mathrm{C}$ line of $850 \mathrm{hPa}$ is stretched to $\mathrm{Hu}$ bei. Meanwhile, the ground has cold high pressure, and the center pressure is greater than $1025 \mathrm{hPa}$. These findings could be used for adjusting crop structure, select suitable varieties for growth in Hunan and predicted abnormal
\end{abstract}


frost disasters for effective prevention.

\section{Keywords}

Frost Days, Temporal and Spatial Characteristics, Circulation Characteristics

\section{Introduction}

Frost, similar to the freezing weather of rain and snow, is a severely affected weather in China (Lin et al., 2000; Wu et al., 2003; Shen et al., 2003), especially for crops. For example, in 1996, severe frost occurred in southern China. Many tropical crops suffered serious damage and lost billions of dollars. In 1982, the frost in the middle and lower reaches of the Yangtze River caused the freezing rate of Hunan Changde decreased to 80\% (Song \& Cai, 2007); in 1999, most of Fujian Province After suffering from the most serious frost disaster in decades, the province's crops affected by disasters and disasters reached 26.0, 221,000 hectares respectively, and the economic losses amounted to several hundred million yuan ( $\mathrm{He} \& \mathrm{Wu}, 2012)$.

Regarding the frosty weather and climate background, many scholars have carried out research on frost weather in the country (Ye \& Zhang, 2008; Wang et al, 2009; Du \& Ning, 2006). For example, Xu et al. (2009) studied the variation characteristics of the Chinese frost period from 1957 to 2006. Some provinces such as Qinghai (Chen et al., 2009), cities such as Guangzhou and Dalian (Wen et al., 2010; Wang et al., 2008; Pei et. al., 2007) also carried out statistics and diagnosis on the region. Shen et al. (2018) study the characteristics of the early frost on the Sanjiang Plain and the mutation index. There are also many frosts abroad. There are also many studies on frost weather outside of China (Easterling, 2002). Huang \& Wang (2008) introduced the mechanism of detecting frost affecting crops that cause crop damage. The main crops affected by frost weather are cotton, rape, cabbage, spring corn, millet and potato (Li et al., 2012). In general, frost weather is closely related to daily minimum temperature, precipitation, Xiang to humidity, wind speed, sunshine, total cloud amount and other factors (Duan et al., 2013). Therefore, although the statistical analysis based on frost weather has been analyzed by many scholars, the research work has mostly been before the early 21 st century. Many studies have shown the important role of atmospheric circulation in the weather (Vicente-Serrano et al., 2008; Cheng et al., 2018), but the analysis of the circulation background of frost weather is still low. It is still necessary to further the frost weather study.

Hence, we used 97 ground-based meteorological observation stations in $\mathrm{Hu}$ nan Province to observe the daily frost observation data in 2017, and carry out statistical analysis on the climate change characteristics of frosty weather in $\mathrm{Hu}$ nan Province, and summarize the circulation situation of frosty weather, in order to make the crop structure of Hunan region. Adjusting and selecting the basis for the varieties with suitable growth period has important guiding signific- 
ance for improving the prediction ability of abnormal frost disasters in Hunan, effectively preventing frost disasters and increasing crop yield.

\section{Data and Methods}

\subsection{Data}

The selected meteorological data comes from the Climate Center of Hunan Province, China. Due to the different time of station construction, there were certain differences in the starting time of each station data, the earliest date is 1951 , the latest is 1981 , but most of the station data is from the top. It was created in the 1950s. For the convenience of statistics presentation, in the past years, the date of the initial and final frosts is expressed in Japanese order from January 1 st, that is, the date of January 1 is 1 , and the date of February 5 is 36 . The date of October 4 th is 277.

\subsection{Methods}

The frost, the number of days, months, and years were analyzed, and the variation characteristics, extreme values, and persistence analyzed. The trend is shown by linear and polynomial fitting methods. In addition, the date when the first frost occurs during the transition from the warm season to the cold season is the first frost day, and the last frost from the cold season to the warm season is the final frost date, and the day after the final frost date is the first frost. The number of days between the previous days of the date is called the frost-free period. The maximum inter-annual dispersion of the initial and final frost dates and the frost-free period is expressed by the range; the inter-annual rate of change of the initial and final frost dates and the frost-free period is measured by the standard deviation; the province's average time series is the annual data is obtained by arithmetic. The formula for calculating the frost standard deviation of each weather station is as follows:

$$
s=\sqrt{\frac{1}{n-1} \sum\left(x_{i}-\bar{x}\right)^{2}},
$$

where, $S$ is the standard deviation, $n$ is the number of samples, $x_{i}$ is the number of frost days per year, which $x$ is the average.

\section{Results and Analysis}

\subsection{Abbreviations and Acronyms}

It can be seen from Figure 1 that the average annual frosty day is gradually decreasing from northeastern Hunan to southwestern Hunan. The areas with the frostiest weather in Hunan Province are Changde, Yueyang, Yiyang and northern Changsha in the north of Hunan, near Shuangfeng in Xiangzhong and southeast of Hunan. In Zhuzhou and southern Zhangzhou, the annual average frost days in these three regions reached more than 20 days, with Linsheng's 30.5 days being the largest. Southwest Hunan is below 12 days, Jianghua County is 


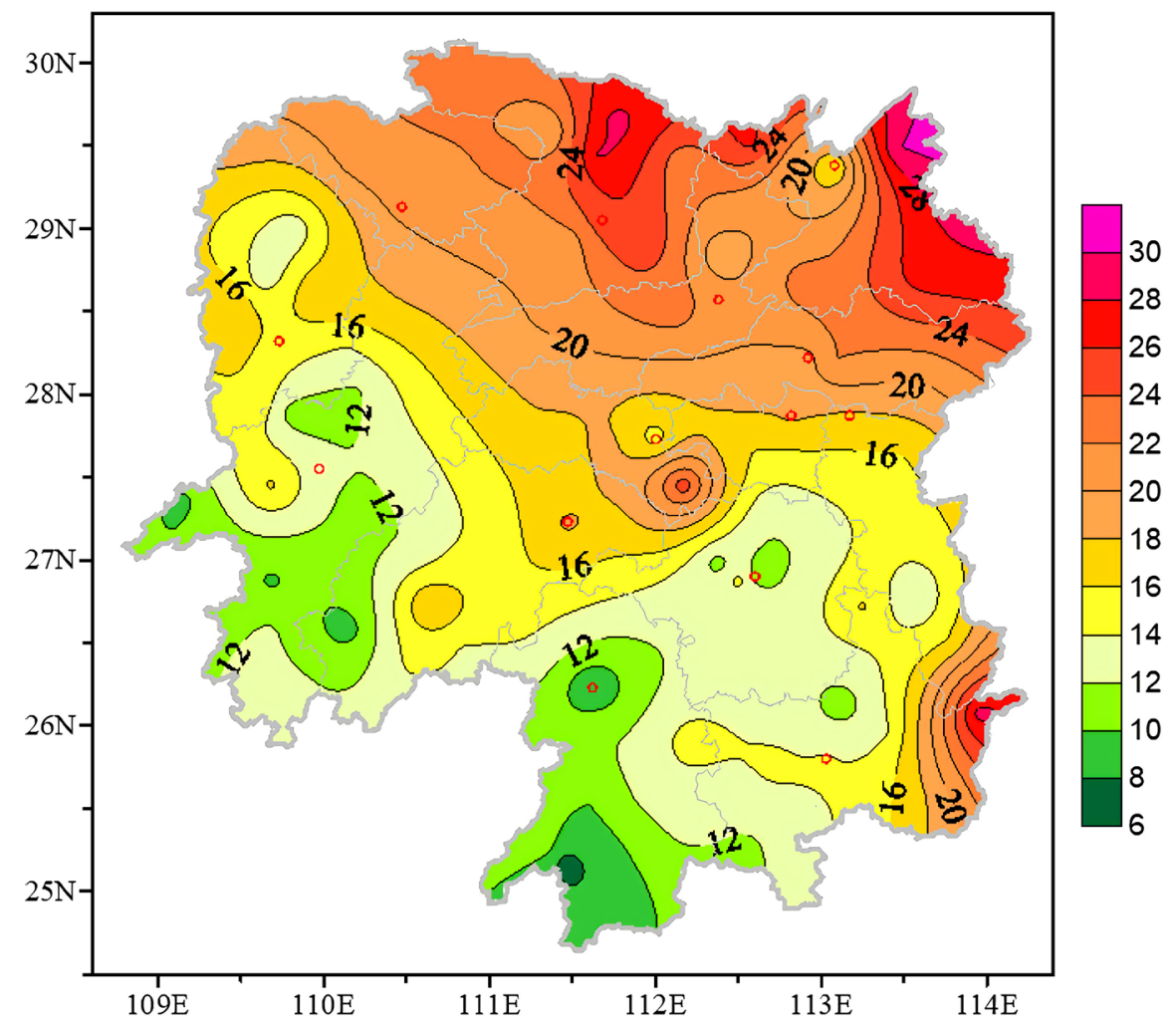

Figure 1. Distribution of the average frost dates in Hunan (unit: day).

the least, 7.36 days, followed by Yongzhou 7.86 days. In general, the frosty weather in our province has obvious geographical distribution characteristics. In the northeastern region and high-altitude mountainous areas, it is affected by cold air, cooling is faster, frosty weather is easy to appear; in the south, it is opposite.

From the distribution of the maximum frost days of each weather station in 1951-2017 (Figure 2(a)), the maximum frost day is generally characterized by the decreasing of northeastern Hunan to southwestern Hunan, but the eastern part of southeastern Hunan also has more frost days, namely Yueyang and Yiyang. The largest frost days in Changde and eastern Zhangzhou are more, while the largest frost days in Xiangxi, Huaihua, South, Shaoyang, Hengyang and Zhangzhou are less; the maximum frost days appear in Pingjiang and Xiangdong in northeastern Hunan. In the eastern part of Guidong, it reached 54 days, which appeared in 1963 and 1971 respectively. The minimum value of the largest frost day appeared in Yongzhou, 18 days, appeared in 1975, followed by Xinhuang for 20 days, which appeared in 1993. The third small value was 21 days in Dao County and appeared in 1975 and 1986.

The area with a minimum frost day of more than 10 days is distributed in Xiangbei (Figure 2(b)), mainly located in the eastern and northern parts of Yueyang, north of Changde; less than 2 days mainly distributed in Xiangxi and Xiangnan, including the western part of Zhangjiajie, most of Xiangxi, and the middle and south of Huaihua, Shaoyang In the west, most of Hengyang, the 


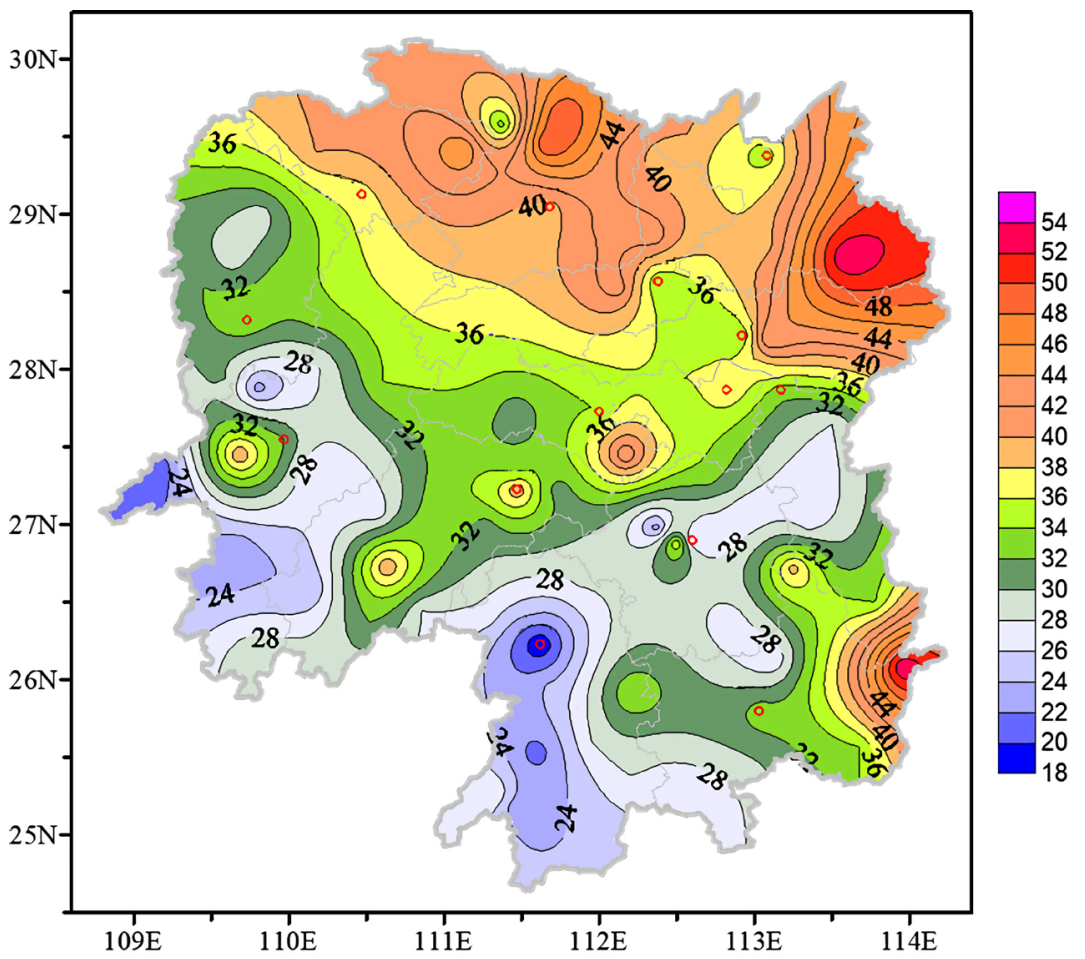

(a)

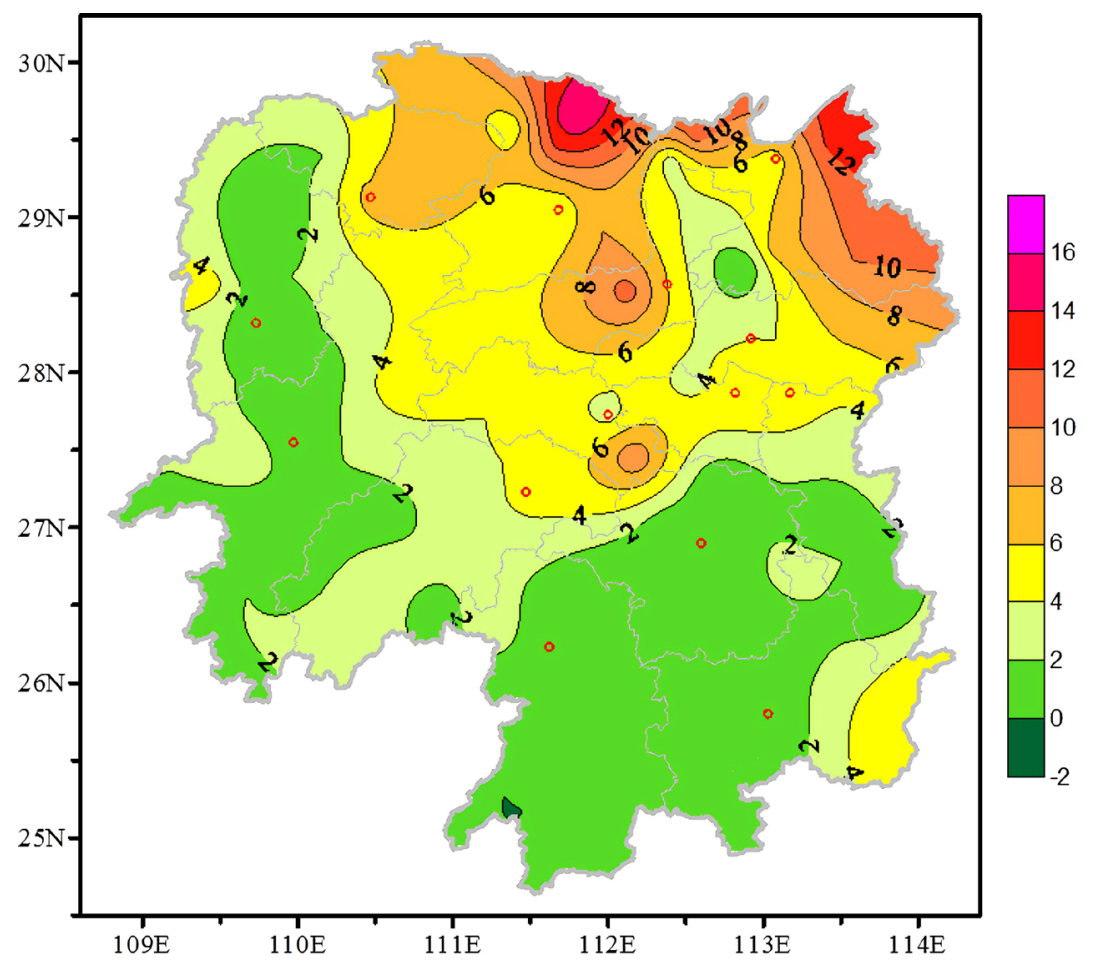

(b)

Figure 2. Distribution of frost dates in Hunan province during 1951-2017 ((a) maximum, (b) minimum).

southern part of Zhuzhou, Yongzhou and most of Zhangzhou. The maximum value of the minimum frost day appeared in Jixian County, which was 16 days, 
which appeared in 2002, followed by Linxiang, which was 13 days, appeared in 2015, more than 10 days, Linyi (appeared in 1959), Taojiang (Appeared in 1997 and 2015). The minimum value of the minimum frost day is 0 days. A total of 14 counties have a frosty day of 0 . They are mainly distributed in southeastern $\mathrm{Hu}$ nan. There are also scattered counties in northwestern Hunan and northern Hunan, and there are no frosts. 1957), Jishou (1957), Xiangyin (1993), Nanyue (1953), Huitong (1957), Fuyang (1957), Hengyang County (2015), Yanling (1957), Yong Xing (1959, 2000), Ningyuan (1959), Jiang Yong (2015), Yizhang (1957), Jianghua (1957, 1991, 1996, 2015); from time to time, 1953, 1957 In 1959, 1991, 1996, 2000 and 2015, there were no frost days on the site, mainly in the 1950s and 1990s. Among them, there were up to 7 counties in 1957, followed by 3 in 2015.

Further analysis of the standard deviation of frost days on various county stations in Hunan Province (Figure 3), the large standard deviation of frost day is mainly located in the north of Hunan, the southeast of Hunan, and the eastern part of Changsha. The maximum value is in Guidong, Zhangzhou, which is 9.96 days. Secondly, the Pingjiang River in Yueyang City is 9.54 days. More than 8 days have Sangzhi, Nanxian, Mapoling and Shuangfeng, indicating that the frost days in these areas have changed greatly over the years, and the risk is much higher when assessing climate resources. The average frost days in the two regions with large frost dates (Northeast and Southeast) are also noteworthy. The smaller standard deviation of frost day is mainly located in southwestern Hunan

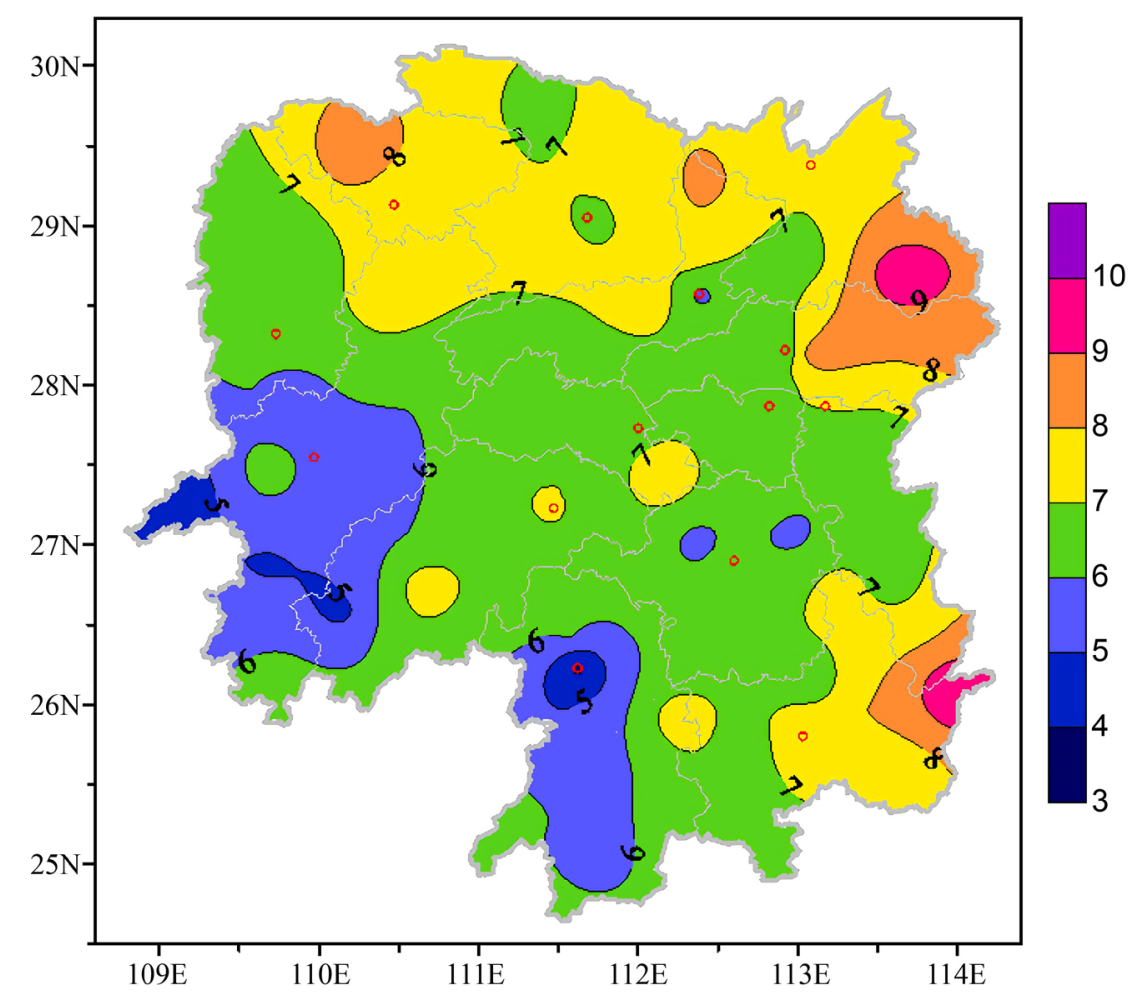

Figure 3. Distribution of the standard deviation of the frost dates in Hunan Province during 1951-2017. 
and southeastern Hunan. The area less than 6 days is mainly in the south of Xiangxi, the middle and south of Huaihua, the west of Shaoyang and the majority of Yongzhou. The minimum value is 3.77 days in Yongzhou, followed by Xinhuang. 4.30 days, less than 5 days, there are Huitong, Suining, Dao County, so the frost days in these areas fluctuate less, and the risk is relatively small when assessing agricultural climate resources. A fully quantitative risk assessment is more complex (He \& Shao, 2011) and is subject to further research.

In 1951-2017, the frosty day of Hunan Province totaled 1098 days, with an average annual rate of 16.39 days. It can be seen that the frequency of frosty weather in Hunan Province is relatively high. From the average frost day change curve (black embedded triangle solid line) in Figure 4, the overall downward trend, the climate tendency rate is $0.1 \mathrm{~d} / \mathrm{a}$, passed the significance test of 0.001 . Before 1971, the number of frost days in Hunan Province increased slightly, from 1971 to 1998 , and then the change was relatively stable, maintaining around 16 days. The maximum frost day appeared in 1963, the province reached 28.64 days, followed by 1993 at 28.53 days and the third at 28.03 days, which appeared in 1971. The year with the least frost day is 2015, with an average of 4.59 days in the province, followed by 1957 , with an average of 7.82 days, and the third less than 7.84 days in 2012.

The time series of Yongdong and the minimum value of Yongzhou, which has the maximum standard deviation of frost in the past 67 years (see the blue and cyan lines in Figure 4), can be seen from the timing chart of Guidong County, indicating that it is generally frosty. There is also a decreasing trend year by year,

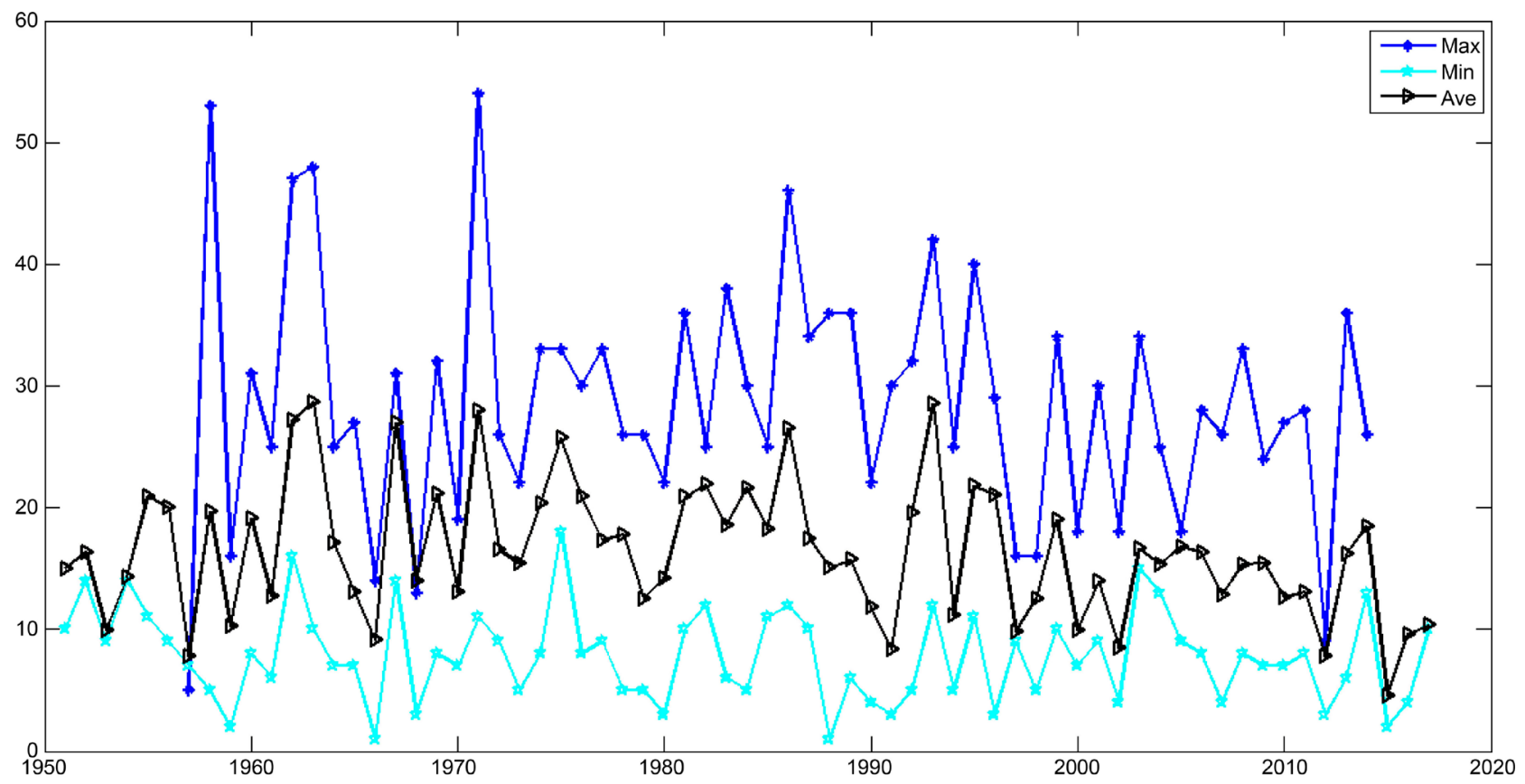

Figure 4. Variations of interannual frost dates during 1951-2017 (black triangle line for interannal average of meteorological station, blue star line and cyan pentagon line for interannual frost date of the station with standard deviation maximum and minmum respectively). 
which is basically consistent with the annual average frost day change trend in Hunan. The maximum frost day is 54 days, which appeared in 1971, followed by 53 days, in 1958, and the third largest was 48 days, which appeared in 1963. In Yongzhou, where the standard deviation of frost is the smallest, the time change is similar to that of the county station with the annual average frost day and the maximum variance, but the change is relatively small, and the annual standard value of the small standard deviation is also small. The maximum appeared in 1975, 18 days, followed by 16 days, in 1962, and 3rd in 15 days, in 2003. The latitudes of Guidong and Yongzhou are similar, but the maximum number of frost days is more than one month. This is because the topography and elevation have an important influence on the formation of frost.

From the average monthly distribution (see Table 1), the frost in Hunan Province appeared from November to March, with the highest from December to January, with $74.2 \%$ of the total, occurring in December and equivalent to what occurred in January. The proportion in November and March is very small, accounting for only $10.8 \%$ in total for two months. From the inter-departmental distribution (see Table 1), the frost weather is the most in late December, accounting for $16.9 \%$ of the total frost days, followed by the first half of January, accounting for $14.4 \%$ of the frost days, and then the late January and January. In the middle and mid-December, there were almost no frosts in early November and mid-March and late March.

\subsection{Characteristics of Climate Change in the Initial and Final Frost Days and Frost-Free Period}

The frosty early and final frost days in Hunan Province also have obvious regional differences. The analysis shows that the average first frost day in Hunan Province is from late November to early December, and the average first frost days in northeastern Hunan and southeast Hunan are the earliest, and the west of Hunan and Hunan are the latest. Especially in Yueyang, Changsha and eastern Zhangzhou, the early appearance of Guidong in Zhangzhou appeared in the middle of October; some areas in Autonomous Prefecture, Huaihua and Yongzhou appeared after November, among which Jianghua, Baojing, Xinhuang, Huitong and Hongjiang appeared in mid-November. The eastern and western parts of Hunan and the southwest are all mountainous areas. Therefore, the first frosty day is gradually advanced from west to east, and the relationship with topography and latitude is not very close.

Table 1. Distribution of monthly and ten days average frost dates during 1951-2017.

\begin{tabular}{cccccc}
\hline Month & November & December & January & February & March \\
\hline Monthly Frost Days & 1.1 & 6.1 & 6.0 & 2.4 & 0.7 \\
Ten-Days Frost Days & $0 / 0.2 / 0.9$ & $1.5 / 1.6 / 3.0$ & $2.3 / 1.9 / 1.8$ & $1.3 / 0.8 / 0.3$ & $0.7 / 0.0 / 0.0$ \\
\hline
\end{tabular}

Notes: In the bottom column "Ten-day Frost days", the slash "/" indicates the division of the first to 10th, the 11 th to 20 th and the 21 st to the end of each month. 
The average final frost day in most parts of Hunan Province is in the middle and late February, showing the distribution characteristics of "Northern Night South Morning", that is, the earliest end of Xiangnan and the end of Xiangbei at the latest, the difference between the two is more than one month. In addition to the eastern part of southeastern Hunan, the end of frost is significantly later than other parts of southern Hunan. The earliest ending was Jianghua County in Yongzhou, Hunan Province, which ended in January; while Sangzhi, Qixian, Anxiang, Nanxian, Huarong, Qijiang, Linxiang, Yueyang, Pingjiang, Liuyang and Guidong ended late. It ended in early March, with the late end of Guidong and the next period in early March.

Hunan's annual average frost-free period shows the distribution pattern of "Northern Short South Long". The northeastern Hunan and southeastern Hunan are below 270 days, and the southwestern Hunan has the longest frost-free period of more than 300 days.

In the southeastern part of Hunan, Guidong has the earliest frost day, the latest frost day, and the frost-free period is the shortest, which may be related to the terrain. Guidong County is surrounded by mountains and has a high altitude. The east is located at the junction of Chongyi County, Jiangxi Province. The main peak of Qiyun Mountain is 2061.3 meters above sea level, which is the first peak in the county. The main peak of Bamian Mountain at the junction of Xixing and Zixing City is 2042.1 meters above sea level. The temperature varies greatly from day to night, which is conducive to the formation of frost and exists due to different topography and altitude. Obvious geographical differences form a microclimate zone with "one mountain and four seasons, ten different days".

Figure 5 shows that Hunan's annual average first frost day shows signs of delay, with a climate tendency rate of $0.13 \mathrm{~d} / \mathrm{a}$. In clear terms, it was delayed in the 1950 s and 1960s, and the changes in the 1970s and 1980s were not obvious. Since the 1990s, there has been a trend of delay, with a difference of 48 days between the earliest and the latest.

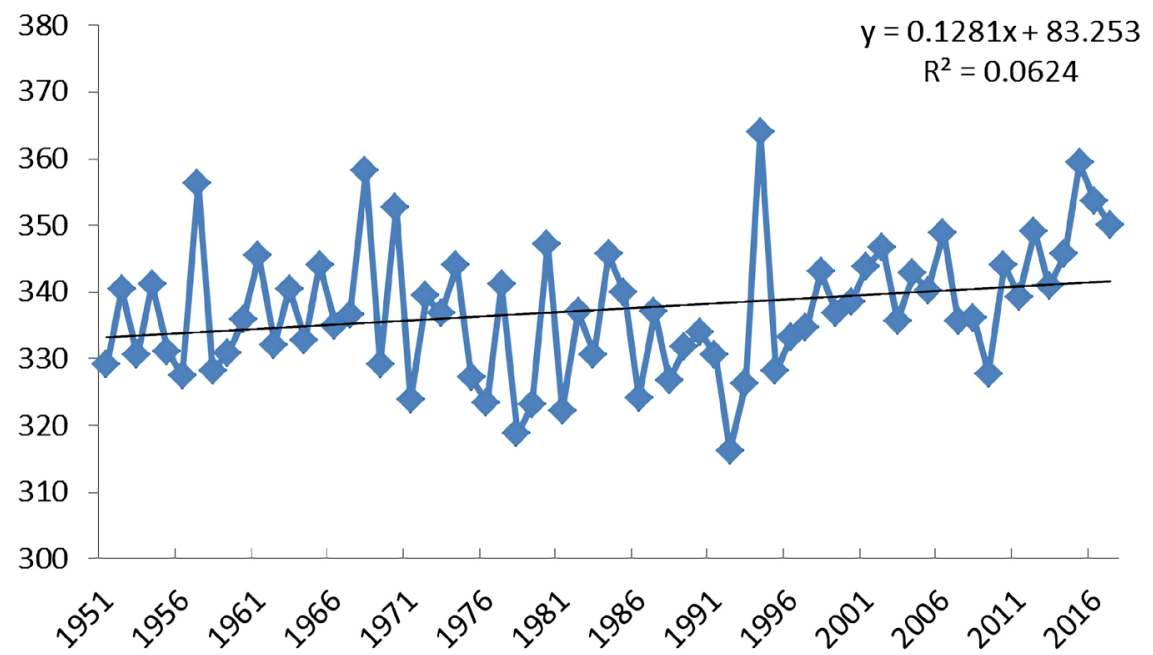

Figure 5. Change in first frost dates averaged in Hunan province during 1951-2017. 
Figure 6 shows that Hunan's annual average frost day shows signs of advance, with a climate tendency rate of $-0.12 \mathrm{~d} / \mathrm{a}$, which was not obvious before the mid-1970s. It was in a relatively late period, after the mid-1970s. There is a clear early trend since the 21 st century, and the difference between the earliest and the earliest is 40 days. The annual average frost-free period in Hunan Province is prolonged, and its climate tendency rate is $0.22 \mathrm{~d} / \mathrm{a}$. It was in a relatively stable period in the 1950s and 1970s, and the change was not obvious. It was shortened in the 1980s and 1990s, but in the 20th century, there has been a significant fluctuation since the beginning of the decade.

\subsection{Analysis of the Concept Model of the Province's Frosty Days}

The situation of the frost day was analyzed using the NCEP four times a day data (resolution $1^{\circ} \times 1^{\circ}$ ). Taking into account the typicality and representativeness, this paper statistically synthesizes the situation field of the province's frosty day (the frosty weather of $\geq 32$ stations in the whole province), understands the background of the frosty weather circulation in the province, and establishes its conceptual model. Figures 7 (a)-(c) show the provincial average frost field at 500 $\mathrm{hPa}, 850 \mathrm{hPa}$, and the ground average.

At $500 \mathrm{hPa}$ (Figure $7(\mathrm{a})$ ), the East Asian trough is located east of $120^{\circ} \mathrm{E}$, the trough bottom extends to $25^{\circ} \mathrm{N}$ south, the 568 dagpm line crosses the northern part of Hunan, the southwest is controlled by the northwest, and the low vortex has a cold zone of $-40^{\circ} \mathrm{C}$. Coordination, the $-28^{\circ} \mathrm{C}$ line passes through the Shandong peninsula, the $-12^{\circ} \mathrm{C}$ line presses south to the south of Hunan; the temperature trough lags behind the height trough, and the cold advection is obvious; the circulation flow is large, and the northwest airflow that is strong after the trough guides the cold air south, affecting the central and eastern regions of China, especially the cold air in the West Road, often cause a large range of sharp cooling.

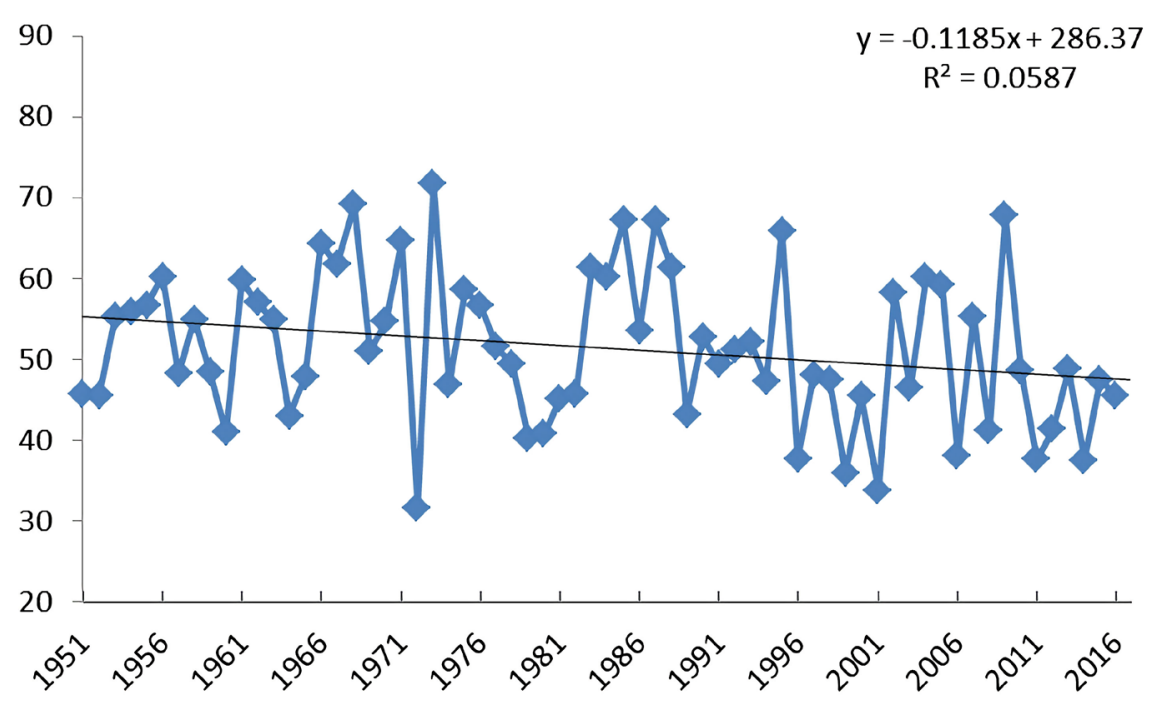

Figure 6. Change in last frost dates averaged in Hunan province during 1951-2017. 


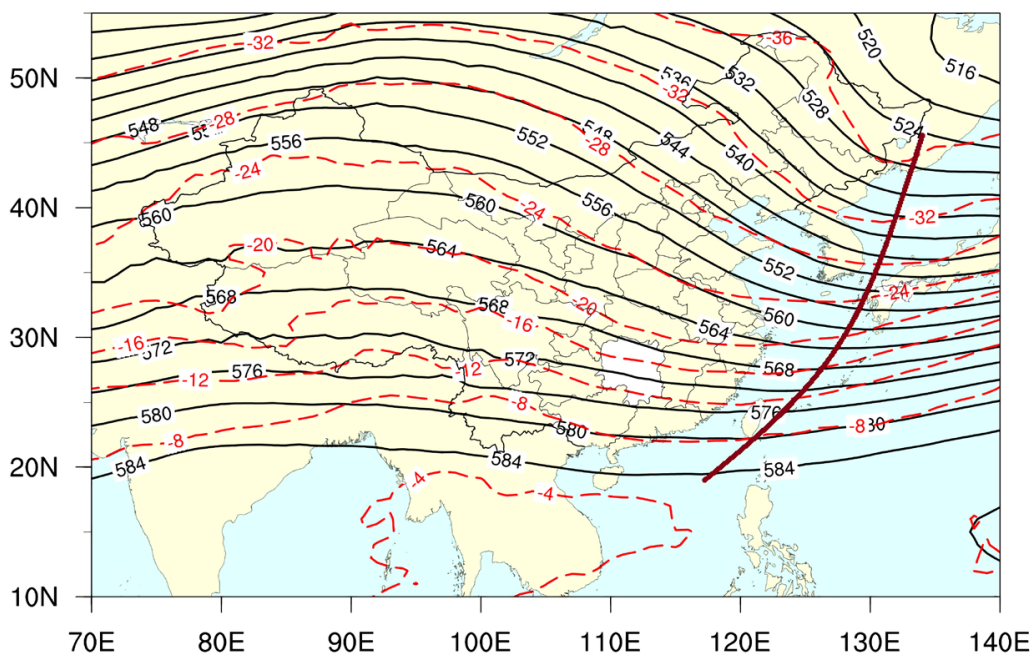

(a)

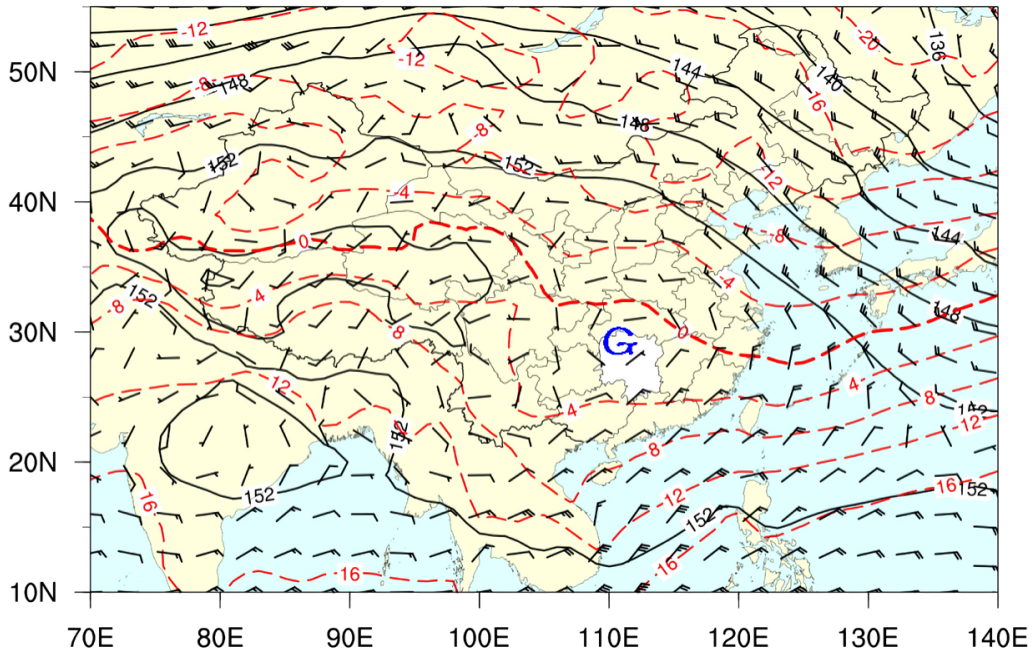

(b)

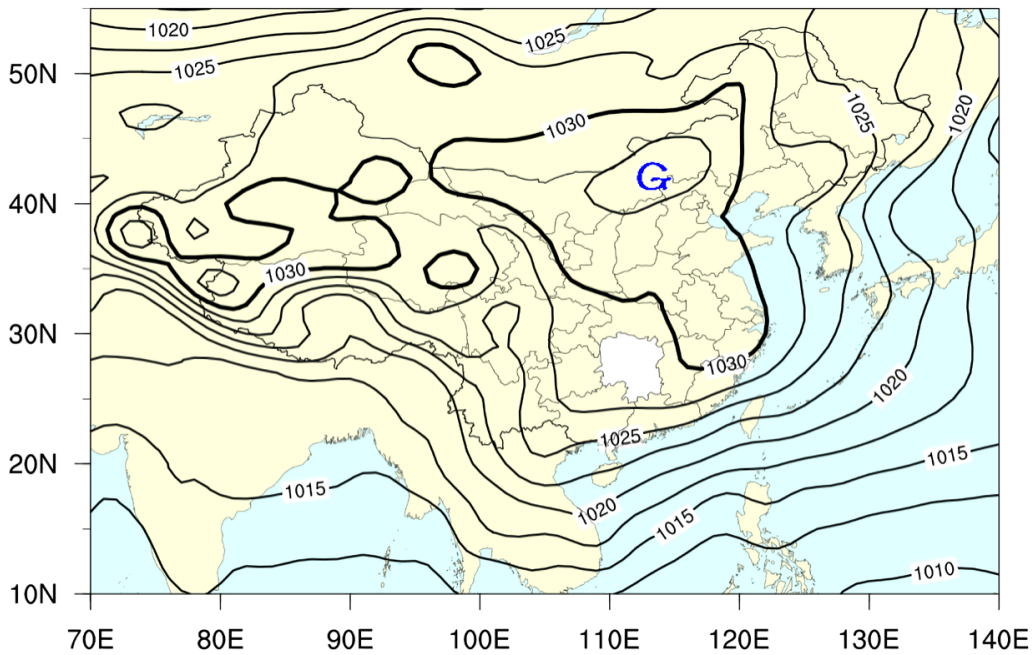

(c)

Figure 7. The synoptic situation of frost dates of the whole province ((a). $500 \mathrm{hPa}$; (b) 850 $\mathrm{hPa}$; (c) sea surface level). 
At $850 \mathrm{hPa}$ (Figure 7(b)), the entire East Asian continent is in the ridge of high pressure. The wind field shows that the high-pressure center is located at the junction of Hubei and Hunan, and Hunan is in the high-pressure circulation. On the temperature field, the eastern coast of China is controlled by the cold trough. It also extends to the south of $25^{\circ} \mathrm{N}$, and the cold and flat flow is strong; the $0^{\circ} \mathrm{C}$ line is located in Hubei.

The mean sea level pressure field (Figure $7(\mathrm{c})$ ), under the control of cold high pressure in most parts of East Asia, the main body of the high-pressure center $(\geq 1030 \mathrm{hPa}$ area) is located in the middle and eastern part of China. Although Hunan is not in the range of $1030 \mathrm{hPa}$, the isobaric line is sparse. Pressure field control, it can be seen that Hunan is within the control range of the ground cold high-pressure circulation. According to the forecasting experience, when the cold high center is located between $26-30^{\circ} \mathrm{N}$, Hunan is controlled by it, mainly in clear weather, and the nighttime radiation is obviously cooled, which is easy to generate frost.

The study found that the corresponding background situation of different frost days is basically similar to the provincial frost day (figure omitted), but there are subtle differences between the north and south positions of the characteristic line (such as $850 \mathrm{hPa} 0^{\circ} \mathrm{C}$ line and sea level pressure $1030 \mathrm{hPa}$ line).

\section{Conclusion and Discussion}

In summary, based on the statistical analysis of Hunan Frost Day data from 1951 to 2017, the following conclusions are made. The frosty weather in Hunan Province of China has obvious geographical distribution characteristics, with the northeast to southwest trend decreasing from north to south. The northern and southeastern high-altitude mountainous areas are more prone than the southwestern part; the first frost day gradually shifts from east to west. Also, the final frost day gradually delays from south to north.

The spatial distribution characteristics of the average frost day and the maximum frost day are basically the same, and gradually decrease from the northeastern Hunan to the southwestern Hunan, but the southeastern Hunan also has a larger center; while the smallest frosty day is more in Xiangbei, Xiangxi and Xiangnan but as mall distribution.

The annual average frost day of Hunan has a slight decreasing trend with time series as the station with the largest standard deviation of the annual frost day has the largest amplitude, and the station with the smallest standard deviation of the annual frost day has the smallest amplitude but basically of similar magnitude. Frosting appears mostly from December to January, but most frequently in late December.

The standard deviation of frost changes in the southeastern part of Yueyang, the eastern part of Changsha and the eastern part of Zhangzhou where it is highest, while the standard deviation of frost on the southern part of Xiangxi Prefecture, the middle and south of Huaihua, and the majority of Yongzhou is 
the least, as the standard deviation is large. The area is relatively risky for agriculture, while the area with a small standard deviation is least risky.

A preliminary analysis of the characteristics of the meteorological circulation in the province's frosty days in Hunan Province shows that the $500 \mathrm{hPa}$ East Asian trough is stable because there is a cold tongue of $-40^{\circ} \mathrm{C}$ in the northeastern part of the temperature field, and the $-12^{\circ} \mathrm{C}$ line to the southern part of Hunan. At $850 \mathrm{hPa}$, the lake located in the high-pressure circulation, has strong cold advection, as the $0^{\circ} \mathrm{C}$ line is pressed to the north of Hunan cold high-pressure control.

\section{Acknowledgements}

This work was supported by the research and business application of frost forecasting and early warning technology in Hunan Province and the short-term plan of Hunan Provincial Meteorological Bureau in 2014 (XQKJ14B081), forecaster special for China Meteorological Administration (CMAYBY2017-050), capacity building project of Hunan Meteorological Bureau in 2016-2017 (YBNL16-12-1) and study on Meteorological Early Warning Zoning of Geological Hazards in Hunan Province.

\section{Conflicts of Interest}

The authors declare no conflicts of interest regarding the publication of this paper.

\section{References}

Chen, F., Wang, Q. C., \& Yin, W. X. (2009). Characteristic of Frost Variation in Recent 45 Years over Qinghai Province and Its Impact on Major Crops. Meteorological Science and Technology, 37, 35-41.

Cheng, X., Yang, B., Liu, G., Olofsson, T., \& Li, H. (2018). A Variational Approach to Atmospheric Visibility Estimation in the Weather of Fog and Haze. Sustainable Cities \& Society, 39, 215-224. https://doi.org/10.1016/j.scs.2018.02.001

Du, J., \& Ning, B. (2006). Analysis of Anomalous First/Last Frost over Middle Reaches of the Yarlung Zangbo River in Tibet from 1961 to 2000. Meteorological Monthly, 32, 84-89.

Duan, L. J., Liao, Y. F., Tang, J. et al. (2013). Study of Frost Monitoring Model: Taking Hunan as an Example. Chinese Agricultural Science Bulletin, 29, 175-182.

Easterling, D. R. (2002). Recent Changes in Frost Days and the Frost-Free Season in the United States. Bulletin of the American Meteorological Society, 83, 1327-1332. https://doi.org/10.1175/1520-0477-83.9.1327

He, F. F., \& Shao, B. F. (2011). Risk Regionalization of Meteorological Disasters Caused by Cryogenic Freezing Rain and Snow in Shanghai. Scientia Meteorologica Sinica, 31 33-39.

He, X. N., \& Wu, X. Y. (2012). Climatic Change Characteristics of Frost Weather in Fujian Province in Recent 30 Years. Straits Science, 68, 3-8.

Huang, Y., \& Wang, H. (2008). Impact on Crops and Defence against Frost. Hunan Agriculture, 10, 13. 
Li, F., Yu, W. J., Zhang, J. X. et al. (2012). Analysis of the Climate Change Characteristics and Periodicity of the First Frost in Shanxi Province in the Past 5 Decades. Transactions of Atmospheric Sciences, 35, 754-761.

Lin, L. X., Xue, D. Z, Liang, J. et al. (2000). Climatic and Its Change Characteristics of Frost in Guangdong in Recent 20a. Guangdong Meterological Monthly, 4, 7-9.

Pei, H. Q., Guo, L. N., Zhang, K. X. et al. (2007). The Effect of Climate Warming on Agriculture in LinYi. Scientia Meteorologica Sinica, 83, 121-126.

Shen, N. Z., Liang, R. X., Zhao, X. L. et al. (2003). Study on the Characteristics of the Distribution of the First and Late Frost Dates in Harbin Region. Journal of Northeast Agricultural University, 31, 129-136.

Shen, S. H., Zhong, Y. X., \& Li, P. F. (2018). Study on the Characteristics of Early Frost in Sanjiang Plain Area in Recent 54 Years. Journal of the Meteorological Sciences, 38, 378-384.

Song, D. Z., \& Cai, S. S. (2007). Meteorological Disaster Dictionary of China: Fujian Volume (pp. 221-228). Beijing: China Meteorological Press.

Vicente-Serrano, S. M., Grippa, M., Toan, T. L., \& Mognard, N. (2008). Role of Atmospheric Circulation with Respect to the Interannual Variability in the Date of Snow Cover Disappearance over Northern Latitudes between 1988 and 2003. Journal of Geophysical Research Atmospheres, 112, 44-48. https://doi.org/10.1029/2005JD006571

Wang, G. F., Xu, Y., Zhu, Y. J. et al. (2009). The Spatial and Temporal Characteristics and Trend of Frost Days over China for the Past 50 Years. Meteorological Monthly, 35, 61-67.

Wang, X. P., Ren, G. Y., Zhao, C. Y. et al. (2008). Characteristics of First/Last Frost Date Events and Frost-Free Period in Dalian Area during Recent 46 Years. Journal of Applied Meteorological Science, 19, 673-678.

Wen, J., Hu, L. T., Li, X. et al. (2010). Inter-Annual and Inter-Decadal Variations of the Frost in Guangzhou during the Past 55 Years. Guangdong Meteorology, 32, 1-3.

Wu, X. G., Gao, A. N., \& Chen, Y. G. (2003). Characteristic Indices of Abnormal Frostbite Weather Process of Guangxi. Guangxi Sciences, 10, 72-74.

Xu, Y., Wang, G. F., \& Wang, P. X. (2009). Climatic Change of Frost in China in Recent 50a. Scientia Meteorologica Sinica, 29, 427-433.

Ye, D. X., \& Zhang, Y. (2008). Characteristics of Frost Changes from 1961 to 2007 over China. Journal of Applied Meteorological Science, 19, 661-665. 